\title{
Cartilha de alfabetização e cultura escolar: Um pacto secular
}

\author{
Maria do Rosário Longo Mortatti*
}

\begin{abstract}
RESUMO: No Brasil, a partir da última década do século XIX, com a organização republicana da instrução pública, observa-se o início de um movimento de escolarização das práticas de leitura e escrita e de identificação entre o processo de ensino inicial dessas práticas e a questão dos métodos. A partir de então, a cartilha vai-se consolidando como um imprescindível instrumento de concretização dos métodos propostos e, em decorrência, de configuração de determinado conteúdo de ensino, assim como de certas silenciosas, mas operantes, concepções de alfabetização, leitura, escrita e texto, cuja finalidade e utilidade se encerram nos limites da própria escola e cuja permanência se pode observar até os dias atuais. O objetivo deste artigo é, mediante análise dessas questões, problematizar a relação entre cartilha de alfabetização e cultura escolar e seus desdobramentos na história da educação e da alfabetização em nosso país.
\end{abstract}

Palavras-chave: Cartilha, alfabetização, ensino da leitura, cultura escolar, história da alfabetização

Necessidade apontada desde o final do século XIX no Brasil, o processo de nacionalização do livro didático - produzido por brasileiros e

\footnotetext{
* Professora Adjunta - FFC - Unesp/Marília; Coordenadora do grupo de pesquisa "História do ensino de língua e literatura no Brasil" e do projeto integrado de pesquisa "Ensino de língua e literatura no Brasil: Repertório documental republicano" (Apoio CNPq e FAPESP). E-mail: mrosario@sunline.com.br
} 
adequado à realidade brasileira - acompanha pari passu o anseio de organização republicana da instrução pública; e, simultaneamente, faz-se acompanhar do surgimento e da expansão do mercado editorial brasileiro, que na escola encontra espaço privilegiado de circulação e público consumidor de seus produtos.

No entrecruzamento desses anseios e iniciativas, o ensino inicial da leitura ${ }^{1}$ é tomado como problema estratégico, tornando-se um importante índice para medir a eficácia da escola em relação ao cumprimento da promessa com que acena às novas gerações e que a caracteriza e justifica: o acesso ao mundo público da cultura letrada. Inicia-se, assim, um movimento de escolarização das práticas culturais de leitura e escrita e sua identificação com a questão dos métodos de ensino. Lugar de destaque, passam, então, a ocupar as tematizações, normatizações e concretizações sobre esse ensino e sobre um tipo particular de livro didático, a cartilha, na qual se encontram o método a ser seguido e a matéria a ser ensinada, de acordo com certo programa oficial estabelecido previamente.

Embora já na segunda metade do século XIX encontrem-se cartilhas produzidas por brasileiros, o impulso nacionalizante nessa área se faz sentir, especialmente em alguns estados, a partir da década de 1890, solidificandose nas primeiras décadas do século $X X$, quando se observa o engendramento de fenômenos correlatos: apoio de editores e especialização de editoras na publicação desse tipo de livro didático; surgimento de um tipo específico de escritor didático profissional-o professor; e processo de institucionalização da cartilha, mediante sua aprovação, adoção, compra e distribuição às escolas públicas, por parte de órgãos dos governos estaduais.

Acompanhando o movimento histórico das tematizações, normatizações e concretizações sobre a questão dos métodos, as primeiras cartilhas brasileiras, produzidas sobretudo por professores fluminenses e paulistas através de sua experiência didática, baseavam-se nos métodos de marcha sintética (processos de soletração e silabação). Dever-se-ia, assim, iniciar o ensino da leitura com a apresentação das letras e seus nomes, de acordo com certa ordem crescente de dificuldade. Posteriormente reunidas as letras em sílabas e conhecendo-se as famílias silábicas, ensinava-se a ler palavras formadas com essas sílabas e letras e, por fim, 
ensinavam-se frases isoladas ou agrupadas. Quanto à escrita, esta restringia-se à caligrafia e seu ensino, à cópia, ditados e formação de frases, enfatizando-se a ortografia e o desenho correto das letras.

\begin{tabular}{lllll}
\multicolumn{8}{c}{$2^{\underline{a}}$ lição } \\
va & ve & vi & vo & vu \\
ve & va & vo & vu & vi \\
vo & vi & va & ve & vu \\
& vai & viu & vou &
\end{tabular}

VOCABULOS

$\begin{array}{llll}\text { vo-vó } & \text { a-ve } & \text { a-vô } & \text { o-vo } \\ \text { vi-va } & \text { vo-vo } & \text { ou-ve } & \text { u-va } \\ \text { ui-va } & \text { vi-vi-a } & \text { vi-ú-va }\end{array}$

EXERCICIO

vo-vó viu a a-ve

a a-ve vi-ve e vô-a

eu vi a vi-ú-va

vi-va a vo-vó

vo-vô vê o o-vo

a a-ve vo-a-va

Exemplo 1 - Página da Cartilha da Infância, de T.A.B. Galhardo. Rio de Janeiro:

Francisco Alves, 189?, p. 11

Fonte: Centro de Referência para Pesquisa Histórica em Educação (Unesp-

Marília)

As cartilhas produzidas sobretudo no início do século XX, por sua vez, passaram a se basear programaticamente no método de marcha analítica (processos de palavração e sentenciação), a partir das contribuições da pedagogia norte-americana, divulgadas inicialmente no estado de São Paulo pelas reformas da instrução pública na década de 1890 e posteriormente disseminadas para outros estados brasileiros, por meio de "missões de professores" paulistas. ${ }^{2}$ Embora muitas tenham sido as disputas sobre as diferentes formas de processuação do método, um ponto em comum era a necessidade de se adaptar esse ensino às necessidades biopsicológicas da criança, cuja forma de apreensão do mundo era tida como sincrética. 
Uma nova concepção de criança - de caráter psicológico - passa a embasar a discussão sobre o método de ensino da leitura (e da escrita). Empreendida por educadores, essa discussão prioriza as questões didáticas, ou seja, o como ensinar, com base na definição das habilidades visuais, auditivas e motoras do aprendiz. A partir de então, observa-se um movimento de institucionalização do método analítico, que se consolida com a publicação das Instruções práticas para o ensino da leitura pelo methodo analytico - modelos de lições, expedidas pela Directoria Geral da Instrucção Publica do Estado de São Paulo, em 1915. Nesse documento passa-se a priorizar a historieta (conjunto de frases relacionadas entre si por meio de nexos lógicos), como núcleo de sentido e ponto de partida para o ensino da leitura, enfatizando-se as funções instrumentais desse ensino.

\section{$1^{\text {a }}$ Lição}

Eu vejo uma menina.

Esta menina chama-se Maria.

Maria tem uma boneca.

A boneca está no colo de Maria.

Maria está beijando a boneca.

Exemplo 2-Página de Instrucções praticas para o ensino da leitura pelo methodo analytico - modelo de lições. São Paulo: Directoria Geral da Instrucção Publica, 1915, p. 7

Fonte: Centro de Referência para Pesquisa Histórica em Educação (Unesp-Marília)

E as cartilhas produzidas a partir de então buscam se adequar a essas instruções.

1. Esta é a vaca do meu tio Carlos.

2. Chama-se Rosada.

3. Chama-se Rosada, porque é vermelha.

4. Rosada tem um lindo bezerro.

5. O bezerro é tambem vermelho.

6. Elle gosta muito do leite da Rosada.

7. ? Vocês tambem gostam de leite?

8. Eu gosto muito de leite.

9. Gosto do leite quando tem nata. 
10. É da nata que se faz a manteiga.

11. É da nata que tambem se faz o queijo.

12. ! Não mames todo o leite, bezerrinho!

13. Deixa um pouco de leite para mamãe fazer manteiga.

Exemplo 3 - Página da Cartilha analytica, de Arnaldo de O. Barreto. Rio de Janeiro: Francisco Alves, 191?, p. 48

Fonte: Centro de Referência para Pesquisa Histórica em Educação (UnespMarília)

A partir dos anos de 1930, aproximadamente, as cartilhas passam a se basear em métodos mistos ou ecléticos (analítico-sintético e vice-versa), especialmente em decorrência da disseminação e da repercussão dos testes $A B C$, de Lourenço Filho, cuja finalidade era medir o nível de maturidade necessário ao aprendizado da leitura e da escrita, visando à maior rapidez e eficiência na alfabetização. Verifica-se, então, um processo de secundarização da importância do método, uma vez que o como ensinar encontra-se subordinado à maturidade da criança e as questões de ordem didática, às de ordem psicológica. Observa-se, no entanto, embora com outras bases teóricas, a permanência da função instrumental de ensino e aprendizagem da leitura e da escrita, entendidas como habilidades visuais, auditivas e motoras; e começam a se produzir os manuais do professor acompanhando as cartilhas, assim como se dissemina a idéia da necessidade de um "período preparatório".

\section{$11^{a}$ Lição}

\begin{tabular}{|c|c|c|c|c|}
\hline \multicolumn{2}{|c|}{ Au-va } & \multirow{3}{*}{$\begin{array}{l}\text { vi } \\
\text { viu }\end{array}$} & \multirow{3}{*}{$\begin{array}{l}\text { vo } \\
\text { vão }\end{array}$} & Oo-vo \\
\hline va & ve & & & vu \\
\hline & via & & & \\
\hline va-la & | & vi-va & | & va-le \\
\hline ve-la & | & vo-vô & | & va-ca \\
\hline vi-la & | & vi-via & | & ve-a-do \\
\hline vo-a & | & va-lia & | & vi-da \\
\hline vo-a-va & | & & | & vi-ú-va \\
\hline
\end{tabular}


1. Es-te ca-va-lo é do Vi-ta-li-no.

2. Vi-ta-li-no é o meu ti-o.

3. Ele vi-ve na vi-la.

4. O ca-va-lo tem o no-me de Vu-vu.

5. É um ca-va-lo bem bom.

6. Va-mos, Vu-vu! Va-mos à vi-la.

7. Va-mos, Vu-vu!

Exemplo 4 - Página da Cartilha do povo, de M.B. Lourenço Filho. São Paulo: Melhoramentos, 1928, p. 15

Fonte: Centro de Referência para Pesquisa Histórica em Educação (UnespMarília)

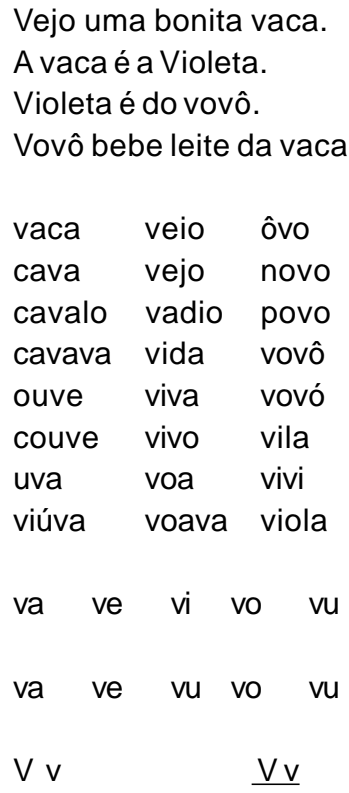

Exemplo 5 - Página da cartilha Caminho suave, de Branca A. de Lima, $8^{\mathrm{a}}$ ed., São Paulo: [ed. da autora],1954, p. 23

Fonte: Centro de Referência para a Pesquisa Histórica em Educação (UnespMarília) 
A partir dos anos de 1980, passa-se a questionar programaticamente a necessidade dos métodos e da cartilha de alfabetização, em decorrência da intensa divulgação, entre nós, dos pensamentos construtivista e interacionista sobre alfabetização.

No entanto, esses questionamentos parecem ter sido satisfatoriamente assimilados, resultando: no paradoxo da produção de cartilhas "construtivistas" ou "socioconstrutivistas" ou "sociointeracionistas"; na convivência destas com cartilhas tradicionais, ${ }^{4}$ nas indicações oficiais e nas estantes dos professores, muitos dos quais alegam tê-las apenas para consulta quando da preparação de suas aulas; e no ensino e aprendizagem do modelo de leitura e escrita veiculado pelas cartilhas, mesmo quando os professores dizem seguir uma "linha construtivista" ou "interacionista" e seus alunos não utilizam diretamente esse instrumento em sala de aula, como ocorreu nos casos transcritos a seguir.
A bola é do Guto.
$O$ gato furou a bola.
O Guto e o gato.

Exemplo 7-Página do caderno de um aluno de 1를érie de escola particular, em 1989 Fonte: Centro de Referência para Pesquisa Histórica em Educação (UnespMarília)

1) A uva é da titia.

2) O cavalo é a uva.

3) O ovo é do titio.

4) A vila é bela.

\begin{abstract}
Exemplo 8-Página do caderno de uma aluna do Ciclo Básico (1 ${ }^{\underline{a}}$ série) de escola pública, em 1995

Fonte: Centro de Referência para Pesquisa Histórica em Educação (UnespMarília)
\end{abstract}

3

Ao longo desses aproximados 120 anos, a cartilha sofreu alterações relativas ao método e teve aprimorados e atualizados vários de seus aspectos, especialmente o suporte material e os temas abordados nas lições. 
Entretanto, permaneceu até os dias atuais, assim como conservou-se intocada sua condição de imprescindível instrumento de concretização de determinado método, ou seja, da seqüência necessária de passos predeterminados para o ensino e a aprendizagem iniciais de leitura e escrita, e, em decorrência, da configuração silenciosa de determinado conteúdo de ensino, assim como de certas também silenciosas, mas efetivamente operantes, concepções de alfabetização, leitura, escrita, texto e linguagem/ língua. Essas concepções operantes podem ser assim sintetizadas:

- alfabetização: processo de ensinar e aprender o conteúdo da cartilha, de acordo com o método proposto, o que permite considerar alfabetizado o aluno que tiver terminado a cartilha com êxito, ou seja, que tiver aprendido a ler e escrever, podendo, assim, começar a ler e escrever;

- leitura e escrita: instrumentos de aquisição de conteúdos escolares, cuja finalidade e cuja utilidade se encerram nos limites da própria situação escolar, ou seja, de ensino e aprendizagem.

- texto: conjunto de frases, por vezes com nexos sintáticos entre si, constituído de palavras escolhidas de acordo com o nível de dificuldade adequado ao momento de aprendizagem.

- linguagem/língua: expressão do pensamento e instrumento de comunicação, cujo funcionamento assume características especificamente voltadas para a situação de ensino e aprendizagem escolares.

Tais concepções remetem à permanência de um projeto (republicano) de educação que vem sendo objeto de constantes ajustamentos e atualizações, cada vez que se constata uma crise, ou seja, cada vez que a testagem - especialmente por meio dos índices de repetência ou evasão de sua eficácia revela que as crianças estão tendo pouco ou nenhum sucesso na alfabetização. E é no âmbito desse projeto, fundamentado em uma concepção seletiva e normativa de cultura, que se engendra uma cultura escolar, a qual se pode definir como:

certos conteúdos cognitivos e simbólicos, que selecionados, organizados, normatizados e rotinizados, sob o efeito dos imperativos de didatização, constituem habitualmente o objeto de uma transmissão deliberada no contexto das escolas. (Forquin 1993, p. 167) 
Ora, um dos principais aspectos da cultura que se constitui objeto de ensino na escola é precisamente a linguagem/língua, que nos precede, ultrapassa, institui e constitui como seres humanos e sujeitos sóciohistóricos. Daí decorre a importância estratégica, no âmbito desse projeto, da escolarização das práticas de leitura e escrita e seu ensino inicial às novas gerações, assim como sua estreita relação com o engendramento de uma cultura escolar.

Como se observa nos exemplos de lições de cartilhas e cadernos de alunos apresentados no tópico anterior, na história da alfabetização em nosso país podem-se identificar certos conteúdos cognitivos e simbólicos - relacionados com aquelas concepções de alfabetização, leitura, escrita, texto e linguagem/língua -, que, selecionados, organizados, normalizados, rotinizados e didatizados, continuam constituindo objeto de transmissão deliberada, sobretudo mediante a utilização direta ou indireta da cartilha de alfabetização até os dias atuais, a despeito das normatizações oficiais contrárias ${ }^{6}$ e dos avanços da lingüística contemporânea, especialmente na vertente da análise do discurso e da teoria da enunciação em que se fundamentam pensamentos contemporâneos sobre alfabetização, como os de Geraldi (1984, 1991, 1996) e Smolka (1989).

Dessa forma, no âmbito da realização de sua função educativa, mediante processo de transmissão cultural intencional, explícita e organizada para as novas gerações e com base em uma razão pedagógica essencialmente normativa e prescritiva, cuja tentação é o anseio de universalização, na escola brasileira vem-se ensinando e aprendendo uma imagem idealizada de linguagem/língua - e, em decorrência, de leitura, escrita e texto - que constitui o objeto de uma aprovação social e sua versão autorizada, sua face legítima.

Dada a legitimidade e o valor intrínseco que a autoridade pedagógica do professor (ainda) confere a esses conteúdos e o fato de ser a escola o lugar por excelência para se aprender a ler e escrever, mesmo o valor instrumental - relativo ao acesso à instrução e ao mundo público da cultura letrada - anunciado ou desejado para essa aprendizagem é substituído por um valor em sidecorrente de uma finalidade restrita à própria aprendizagem, de modo tal que, à pergunta "Para que aprender a ler e escrever?", uma das respostas possíveis - ou talvez a única - seja: "Para aprendera ler e escrever".

Diferentemente do que aponta Forquin, no que se refere à história da alfabetização no Brasil, a seleção cultural escolar (o que tem valor educativo, 
de acordo com certa escala e juízo de valor) sofreu poucas variações "com a época, ideologias políticas ou pedagógicas dominantes" (op. cit., p. 160), prevalecendo certos aspectos constantes tidos como universais e constitutivos de uma cultura escolar, para cujo engendramento, transmissão e perpetuação, tem-se, aliada ao conservadorismo cultural da escola e do professor, a contribuição fundamental da cartilha de alfabetização.

Baseando-se em uma imagem idealizada de linguagem/língua, assim como substituindo o trabalho de professores e alunos - na medida em que àqueles impõe métodos e contéudos de ensino previamente estabelecidos e questionáveis e, a estes, os alfabetizandos, modelos equivocados de leitura, escrita, texto -, a cartilha de alfabetização institui e perpetua certo modo de pensar, sentir, querer e agir, que, embora aparentemente restrito aos limites da situação escolar, tende a silenciosamente acompanhar esses sujeitos em outras esferas de sua vida pessoal e social, uma vez que:

\begin{abstract}
se o imperativo da "transposição didática" impõe a emergência de configurações cognitivas específicas (os saberes e os modos de pensamento tipicamente escolares), estas configurações tendem a escapar de seu estatuto puramente funcional de instrumentos pedagógicos e de auxiliares das aprendizagens, para se constituir numa espécie de "cultura escolar" sui generis, dotada de dinâmica própria e capaz de sair dos limites da escola para imprimir sua marca "didática" e "acadêmica" a toda espécie de outras atividades (...), sustentando assim com as outras dinâmicas culturais relações complexas e sempre sobredeterminadas, de nenhum modo redutíveis, em todo caso, aos processos de simples reflexo ou de "repartição de tarefas" (...). (Forquin 1993, pp.17-18)
\end{abstract}

Na tragédia Fausto, de J.W. Goethe, o protagonista faz um pacto com Mefistófeles, que the promete satisfazer o desejo de conhecimento, de ampliação dos estreitos limites do saber humano. Logo em seguida, travestido de Fausto, Mefistófeles recebe e promete ajudar um estudante que, "com ânimo robusto e inteiro, / com sangue moço e algum dinheiro", viera manifestar ao sábio Fausto seu modesto desejo de ser instruído, mesmo ciente do penoso fardo que teria que suportar para atingir seu objetivo. 
No Brasil, desde pelo menos a última década do século XIX, a escola vem prometendo, a cada nova geração, o acesso à instrução e ao mundo público da cultura letrada. No entanto, essa promessa assemelha-se à do Mefistófeles travestido: não é o conhecimento o que o falso Fausto lhe oferece, nem é Fausto, o sábio, quem promete instruir o incauto estudante. Assim também, na escola brasileira, o que se tem oferecido aos estudantes é o acesso a certa cultura escolar, mediado especialmente pela cartilha de alfabetização, esse primeiro e emblemático instrumento, substitutivo do trabalho de professores e alunos, que se apresenta como portal do mundo prometido e que forma nossas crianças, no sentido da constituição de um modo de pensar, sentir, querer e agir relacionado com a imagem idealizada de linguagem/língua e com modelos equivocados de leitura, escrita e texto.

Será a cartilha de alfabetização um mal necessário, de fato? Que outras concepções, que outras práticas, que outros conteúdos, que outras finalidades da alfabetização, que outras formas de acesso ao mundo da cultura seriam possíveis, no sentido de romper com esse pacto secular?

\section{Notas}

1. Em virtude de estar abordando fenômenos que ocorrem em um período histórico relativamente longo no qual se observam variações terminológicas e a fim de evitar anacronismos léxico-semânticos, para me referir ao processo de ensino da leitura e escrita na fase inicial de escolarização de crianças, estarei utilizando ora "ensino da leitura", ora "ensino da leitura e da escrita", ora "alfabetização", buscando ser fiel à denominação da época em que se registra sua ocorrência.

2. A respeito da influência dessas missões em outros estados, têm-se, especialmente, Amâncio (2000), que aborda o caso de Mato Grosso e a pesquisa em andamento de Marjorie B.E. Mendes, que aborda o caso do Paraná, ambas integrantes do Grupo de Pesquisa "História do Ensino de Língua e Literatura no Brasil".

3. Como se sabe, o pensamento construtivista resulta das pesquisas sobre a psicogênese da língua escrita desenvolvidas por Ferreiro e Teberosky (1985). Deslocando-se o eixo das discussões do como se ensina para o como se aprende a língua escrita (lecto-escritura), esse pensamento se apresenta como uma "revolução conceitual", demandando abandonarem-se as teorias e práticas tradicionais e desmetodizar-se o processo de alfabetização, abandonando a cartilha. O pensamento interacionista, por sua vez, decorre das proposições de Geraldi $(1984,1991,1996)$, que apresenta proposta para o ensino da língua portuguesa em cujo domínio insere o processo de alfabetização -, baseadas em uma concepção interacionista de linguagem, a qual é retomada por Smolka (1989). De acordo com essa concepção, o texto (discurso) é a unidade de sentido da linguagem e deve ser tomado como objeto de leitura e escrita, estabelecendo-se como conteúdo de ensino, que permite um 
processo de interlocução real entre professor e alunos e impede o uso de cartilhas para ensinar a ler e escrever.

4. É importante ressaltar que a produção intensa de novas cartilhas não impediu a continuidade de circulação das antigas, muitas das quais continuaram a ser utilizadas por várias décadas, após a publicação de suas primeiras edições. A esse respeito, ver Pfromm Neto e outros (1974) e Mortatti $(1998,2000)$.

5. A respeito da distinção entre as concepções de linguagem como expressão do pensamento, instrumento de comunicação e forma de interação e suas implicações para o ensino de língua portuguesa, ver, especialmente, Geraldi (1984).

6. Refiro-me especificamente às propostas curriculares elaboradas, a partir de meados de 1980 , no âmbito de secretarias municipais e estaduais de educação e aos Parâmetros Curriculares Nacionais, elaborados no âmbito do MEC, a partir de 1997.

\section{The literacy first reader and the school culture: A century agreement}

ABSTRACT: In Brazil since the last decade of the XIX century with the republican organisation of the public education, it is observed the beginning of a school movement toward the reading and writing practices and the identification between the process of initial teaching of these practices and the methods issues. Since then the literacy first reader is being consolidated as an essential instrument to concrete the proposed methods. In consequence of certain content of teaching as well as silent but effective conceptions of literacy, reading, writing and text, whose goal and use are limited to the school itself and whose permanence is observed up to nowadays. The objective of this article is to consider the above issues, to question the relationship between the literacy first reader and the school culture and its consequences to the education history and the literacy in our country.

\section{Bibliografia}

AMÂNCIO, L.N. de B. Ensino de leitura na escola primária no Mato Grosso: Contribuição para o estudo de aspectos de um discurso institucional no início do século XX. Tese de doutorado em educação, FFC/Unesp. Marília, 2000.

ARENDT, H. "A crise na educação". In: . Entre o passado e o futuro. Trad. Mauro W.B. Almeida. $2^{2}$ ed. São Paulo: Perspectiva, 1979, pp. 221-247.

ARROYO, L. Literatura infantil brasileira. São Paulo: Melhoramentos, 1968. 
AZANHA, J.M.P. "Cultura escolar brasileira". Revista USP, dez./jan./fev., 199091. no 8, pp. 65-69.

BERTOLLETTI, E.N. "Cartilha do povo e Upa, cavalinho!: O projeto de alfabetização de Lourenço Filho". In: MONARCHA, C. (org.). Lourenço Filho: Outros aspectos, mesma obra. Campinas/SP: Mercado de Letras; Marília/SP: Pós-Graduação em Educação - Unesp - Marília, 1997, pp. 91-117.

BRASLAVSKY, B. Problemas e métodos no ensino da leitura. Trad. A. Minnicucci. São Paulo: Melhoramentos, 1968.

DIETZCH, M.J.M. "Cartilhas: Um mundo de personagens sem texto e sem história". Cadernos de Pesquisa, nov., 1990, o 75, pp. 35-44.

FERREIRO, E. e TEBEROSKY, A. Psicogênese da língua escrita. Trad. Diana M. Lichtenstein e outros. Porto Alegre: Artes Médicas, 1985.

FERREIRO, E. Reflexões sobre alfabetização. Trad. Horacio Gonzales. São Paulo: Cortez, 1985.

FORQUIN, J.-C. Escola e cultura: As bases sociais e epistemológicas do conhecimento escolar. Trad. Guacira Lopes Louro. Porto Alegre: Artes Médicas, 1993.

GERALDI, J.W. (org.). O texto na sala de aula: Leitura \& produção. Cascavel/ PR: Assoeste, 1984.

GERALDI, J.W. Portos de passagem. São Paulo: Martins Fontes, 1991. . Linguagem e ensino: Exercícios de militância e divulgação. Campinas/SP: Mercado de Letras; ALB, 1996.

GOETHE, J.W. von. Fausto. Trad. Jenny K. Segall. Belo Horizonte: Itatiaia, 1987.

HEBRARD, J. "A escolarização dos saberes elementares na época moderna". Teoria \& Educação. Porto Alegre, 1990, oㅡ 2, pp. 65-110.

MORTATTI, M. do R.L. Os sentidos da alfabetização: São Paulo - 1876/1994. São Paulo: Ed. da Unesp, 2000.

. "Alfabetização e modernidade no Brasil". Leitura: Teoria \& Prática (ALB), dez. 1998, no 32, pp. 54-58.

. "Uma proposta para o próximo milênio: O pensamento interacionista sobre alfabetização". Presença Pedagógica. Belo Horizonte/ MG, set.-out., 1999, v. 5, oㅡ 29, pp. 21-27. 
OSAKABE, H. "Considerações em torno do acesso ao mundo da escrita". In: ZILBERMAN, R. (org.). Leitura em crise na escola: As alternativas do professor. Porto Alegre: Mercado Aberto, 1982.

PFROMM NETO, S.; ROSAMILHA, N. e DIB, C.Z. O livro na educação. Rio de Janeiro: Primor/INL, 1974.

SMOLKA, A.L.B. A criança na fase inicial da escrita: Alfabetização como processo discursivo. São Paulo: Cortez; Campinas: Ed. da Unicamp, 1989. 